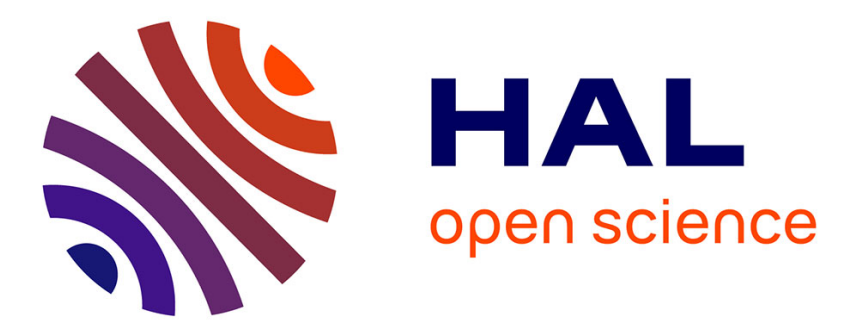

\title{
The Internal Damping of Al-Al2O3 (f) Composites During Thermal Cycling: the Effect of Fibre Content and Matrix Strength
}

S. Urreta, R. Schaller, E. Carreño-Morelli, L. Gabella

\section{- To cite this version:}

S. Urreta, R. Schaller, E. Carreño-Morelli, L. Gabella. The Internal Damping of Al-Al2O3 (f) Composites During Thermal Cycling: the Effect of Fibre Content and Matrix Strength. Journal de Physique IV Proceedings, 1996, 06 (C8), pp.C8-747-C8-750. 10.1051/jp4:19968162 . jpa-00254597

\section{HAL Id: jpa-00254597 https://hal.science/jpa-00254597}

Submitted on 1 Jan 1996

HAL is a multi-disciplinary open access archive for the deposit and dissemination of scientific research documents, whether they are published or not. The documents may come from teaching and research institutions in France or abroad, or from public or private research centers.
L'archive ouverte pluridisciplinaire HAL, est destinée au dépôt et à la diffusion de documents scientifiques de niveau recherche, publiés ou non, émanant des établissements d'enseignement et de recherche français ou étrangers, des laboratoires publics ou privés. 


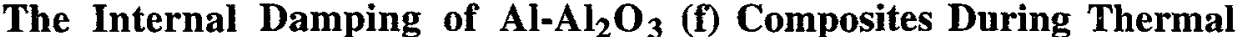 Cycling: the Effect of Fibre Content and Matrix Strength
}

\author{
S.E. Urreta, R. Schaller*, E. Carreño-Morelli*,(1) and L. Gabella* \\ Facultad de Matemática, Astronomía y Física, Universidad Nacional de Córdoba, Ciudad Universitaria, \\ 5000 Córdoba, Argentina \\ * Ecole Polytechnique Fédérale de Lausanne, Institut de Génie Atomique, PHB-Ecublens, \\ 1015 Lausanne, Switzerland
}

\begin{abstract}
A simple model is proposed to describe the observed effect of the volume fraction of fibres on the internal friction, elastic modulus and deformation at zero applied stress during the cooling portion of a thermal cycle between $450 \mathrm{~K}$ and $100 \mathrm{~K}$. The sample is considered as composed by three phases, each one showing different intrinsic damping: the reinforcing fibre, the aluminium matrix far from the fibre and the zone around the fibre, close to the matrix-fibre interface, called the plastic zone. It is assumed that the main contribution to the internal friction arises in these plastic zones, which grow during cooling in a non strain hardening matrix. A uniform dislocation density in the zone is considered. The internal damping of the whole sample is predicted, as a function of fibre content, for the limit case of uniform strain. The model predicts satisfactorily the characteristic temperatures defined in the elastic modulus curve if they are identified as the temperatures for the beginning of growth of the plastic zone, and the temperature for overlapping of fully developed zones, respectively.
\end{abstract}

\section{INTRODUCTION}

The low temperature internal friction spectrum of aluminium matrix composites reinforced with short alumina SAFFIL fibres exhibits large damping effects, not originated in anelastic mechanisms [1]. Similar results have been reported in AlSi alloys containing silicon precipitates [2] and in Al based composites reinforced with $\mathrm{SiC}$ particles and whiskers [3,4]. The common feature in these Al based systems is the coexistence of a soft matrix and a hard reinforcing phase, with a different coefficient of thermal expansion (CTE).

When internal friction is measured as a function of temperature, a long period thermal cycle is imposed to the specimen. Because of this difference in the CTE, large internal stresses are built as the temperature changes. Depending on temperature and the particular matrix microstructure different mechanisms operate to relax these thermal stresses. If they are high enough, dislocations are generated in the softer matrix near the reinforcement and a plastically deforming zone develops [5, 6].

In a previous work [1], the internal friction $\operatorname{tg} \phi$ of $\mathrm{Al}_{-} \mathrm{Al}_{2} \mathrm{O}_{3}$ (fibre) composites during thermal cycles between $100 \mathrm{~K}$ and $450 \mathrm{~K}$ are reported. In addition, the elastic modulus $(M)$ and the torsional deformation at zero applied stress (zero point drift $\gamma$ ) were measured during these thermal cycles. It was found that the internal friction depends on the matrix strength and on the volume fraction of fibres. For a given fibre content, it is directly proportional to the cooling rate and inversely proportional to the strain amplitude and frequency. The elastic modulus and the zero point drift also evidence a clear dependence on the volume fraction of fibres and matrix strength.

During cooling, the elastic modulus tends to stationate in a given temperature range. The extension and the limit temperatures of this range $\left(T_{\text {start }}\right.$ and $\left.T_{\text {end }}\right)$ are different for each fibre content and matrix microstructure.

(1) On leave from Centro Atómico Bariloche and Instituto Balseiro, Comisión Nacional de Energía Atómica and Universidad Nacional de Cuyo, 8400 Bariloche (Argentina) 
The deformation $\gamma$ as a function of the temperature draws a loop. In the less reinforced composite and in the precipitation hardened composite, these are open loops; as $f$ increases or the matrix becomes softer, these loops increase in area and tend to be closed. During cooling a transition temperature may be defined when the composite begins to deform at a higher rate (Figure 1). The torsional deformation $\gamma$ originates in the dislocation rearrangement produced by the internal stress gradients that develop during the measurement.

In the present paper, a simple model is proposed to describe the observed effects of the volume fraction of fibres and the matrix strength on the $\gamma$ deformation (Figure 1), the internal damping (Figure 2) and the elastic modulus (Figure 3) during the cooling portion of the thermal cycle.

\section{THE MODEL}

\subsection{Internal friction in a multiphase sample}

Let us consider a macroscopic ideal composite sample of volume $V$ in which different phases are present such that $f_{i}$ is the volume fraction of phase $i\left(\Sigma f_{i}=1\right)$ and $G_{i}$ its elastic shear modulus. If the interface boundaries transmit stresses perfectly and do not dissipate energy, and these phases are homogeneous, the internal friction of the whole composite becomes:

$$
\operatorname{tg} \phi=\frac{1}{2 \pi} \frac{\sum_{i} \Delta w_{i} f_{i}}{\sum_{i} \frac{1}{2} \frac{\sigma_{i}^{2}}{G_{i}} f_{i}}
$$

where $\Delta w_{i}$ and $\sigma_{i}$ are the energy dissipated in a unit volume and the mean stress in the phase $i$ respectively.

Three different phases are considered in the composite sample: the reinforcing fibres $(F)$, the plastic zone around the fibres $(z p)$ and the "normal" matrix $(M)$, far from the fibres. In the hypothesis of no dissipation in the reinforcement $\left(\Delta w_{F}=0\right)$ and $\Delta w_{z p} \gg \Delta w_{M}$ with $G_{z p} \cong G_{M}$ the internal friction for uniform strain is:

$$
\operatorname{tg} \phi=q_{z p} \frac{f_{z p}}{\left(1+f \frac{G_{F}}{G_{M}}\right)}
$$

where $q_{z p}$ is the intrinsic damping of the plastic zone.

\subsection{Plastic zone development}

At a certain temperature $T_{o}$, the composite is considered to have only two phases, matrix and fibres $\left(f_{z p}=0\right)$, both of them stress free. When it is cooled below this temperature, internal stresses develop until they reach the matrix yield stress at a temperature $T_{\text {start }}$, (see Figure 1). Further cooling below $T_{\text {start }}$ results in the development of the plastic zone.

The temperature $T_{0}$ is closely related to the actual specimen microstructure (dislocation substructure, interfacial micro-cracks, remanent preform ligaments) and can be estimated from the internal friction spectrum. The $\mathrm{Al}-\mathrm{Al}_{2} \mathrm{O}_{3}(\mathrm{f})$ composites exhibit a peak at $450 \mathrm{~K}(1 \mathrm{~Hz})$ [7] arising in dislocation motion controlled by the dragging of solute atoms. Below this temperature, dislocations become pinned by these atoms and creep relaxation is progressively reduced. $T_{0}$ can be estimated as the temperature at which $\operatorname{tg} \phi$ begins to increase during cooling due to an increase in the dislocation activity produced by the developing internal stress gradients.

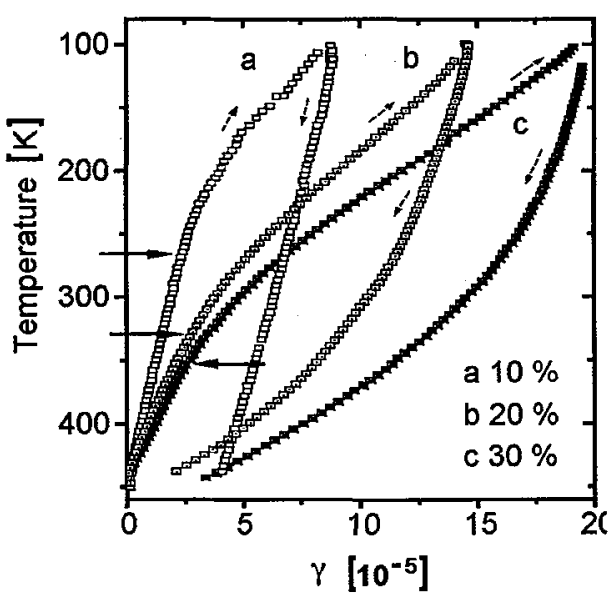

Figure 1: Evolution of $\gamma$ for different volume fraction of fibres. Solid arrows indicate $T_{\text {start }}$ temperatures. 
An approximation for the mean internal stress value in the matrix can be made from the conditions:

$$
\sigma_{F} f+\sigma_{M}(1-f)=0 \quad \varepsilon_{M}-\varepsilon_{F}=\Delta \alpha \Delta T=\left(\frac{\sigma_{F}}{E_{F}}-\frac{\sigma_{M}}{E_{M}}\right)
$$

where $\sigma$ is the thermal stress, $E$ the Young modulus, $\varepsilon$ the stress-free thermal strain of each phase and index $F$ and $M$ refer to fibre and matrix respectively. It results:

$$
\left|\sigma_{M}\right|=\frac{E_{F} E_{M}}{\left(E_{F} f+E_{M}(1-f)\right)} f \Delta \alpha\left(T_{0}-T_{\text {start }}\right)
$$

$T_{\text {start }}$ may be calculated from the temperature change leading to a mean internal stress in the matrix $\sigma_{M}$ close to the matrix yield stress $\sigma_{y 0} \sim 30 \mathrm{Mpa}$. The obtained values are shown in Table I. They are close to the $T_{\text {start }}$ temperatures defined in the modulus (Figure 3 ) and $\gamma$ (Figure 1) curves for each composite. This mean stress approximation disregards the distribution of local stress gradients but it is useful to find the temperature condition at which almost all the fibres induce plastic relaxation in the matrix.

During cooling below $T_{\text {start }}$ the plastic zones develop in the matrix nearby the fibres. Dunand and Mortensen [6] describe the evolution of the radius of the plastic zone around an infinite cylinder of radius $r_{F}$ embedded in a soft matrix as temperature changes. Following this model, and considering that the effect of matrix hardening may be replaced by an effective yield stress in the zone higher than $\sigma_{y 0}$, the plastic zone radius $r_{z p}$ may be approximated by:

$$
\begin{aligned}
& r_{z p}=r_{F}\left[Z_{0}\left(T_{0}-T\right)\right]^{1 / 2} \\
& Z_{0}=\frac{4 \Delta \alpha E_{M}}{(5-4 v) \sigma_{y}}=0.0221 \mathrm{~K}^{-1} \\
& \sigma_{y}=\sigma_{y 0}+\beta \sqrt{\rho}
\end{aligned}
$$$$
\begin{aligned}
r_{F} & =1.5 \mu \mathrm{m} \\
E_{M} & =62 \mathrm{GPa} \\
\Delta \alpha & =16.210^{-6} \mathrm{~K}^{-1} \\
\sigma_{y 0} & =30 \mathrm{MPa} \\
\beta^{\prime} & =9.4 \mathrm{~Pa} \mathrm{~m} \\
\rho & =4.10^{12} \mathrm{~m}^{-1}
\end{aligned}
$$

fibre radius matrix modulus difference in CTE initial matrix yield stress constant dislocation density

Then, the volume fraction of plastic zone is described by the expression:

$$
\left.f_{z p}=f\left[Z_{0}\left(T_{0}-T\right)-1\right)\right]
$$

and the internal friction given in equation (2) becomes:

$$
\operatorname{tg} \phi(f, T)=q_{z p}\left[Z_{0}\left(T_{0}-T\right)-1\right] \frac{f}{(1+6 f)}
$$

Equation (4) indicates that the internal friction in the composite sample depends on fibre content and on matrix strength. When $\sigma_{y}$ increases by precipitation hardening, plastic relaxation may be inhibited as shown in Figure 4, where the alloy composite exhibits no transition in the $\gamma$ behaviour between $450 \mathrm{~K}$ and $100 \mathrm{~K}$.

During further cooling the plastic zones may overlap. Considering an hexagonal packing of cylinders [6] the critical volume fraction of plastic zone $f_{z p}{ }^{*}$ satisfies:

$$
f_{z p}^{*}+f=\sqrt{3} \pi / 6
$$

and the temperature $T_{o v}$ at which the zones touch is roughly given by:

$$
T_{o v}=T_{0}-\frac{\sqrt{3} \pi}{6 Z_{0} f} \approx T_{\text {end }}
$$

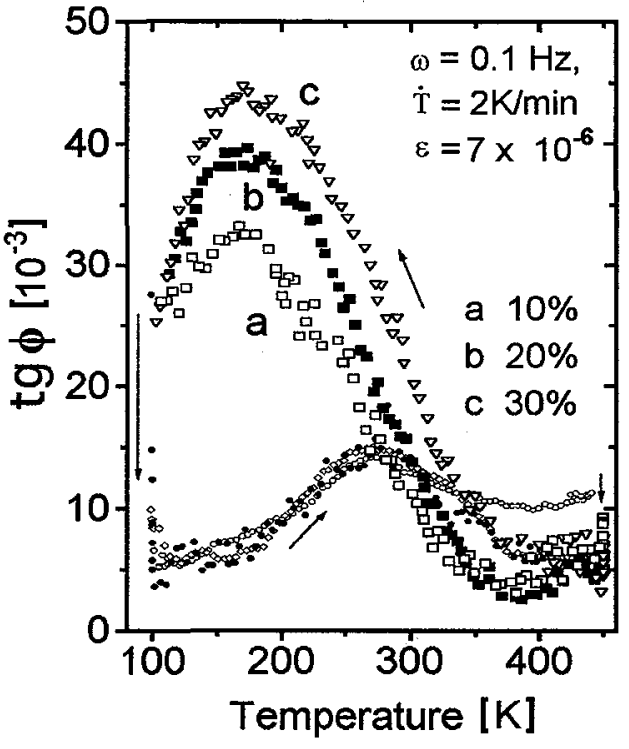

Figure 2: Internal friction in Al based composites with different fibre contents. 


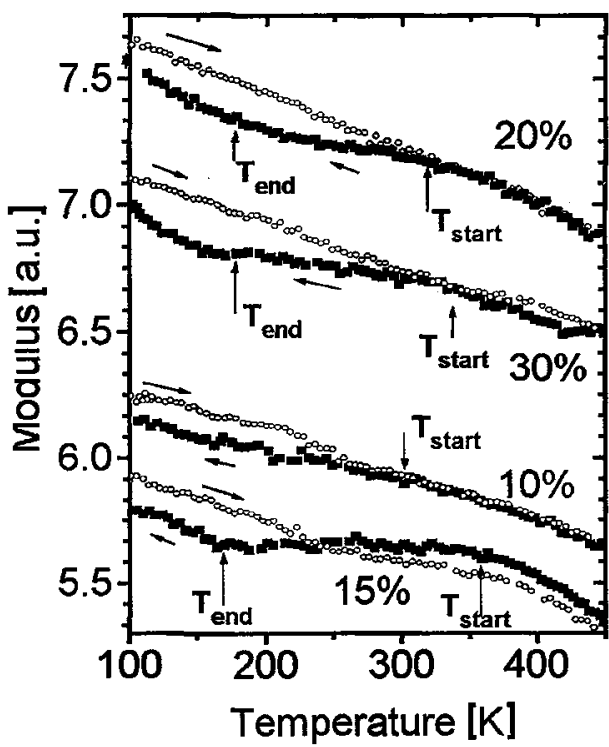

Figure 3: Elastic modulus evolution in $\mathrm{Al}$ based composites with different volume fraction of fibres.

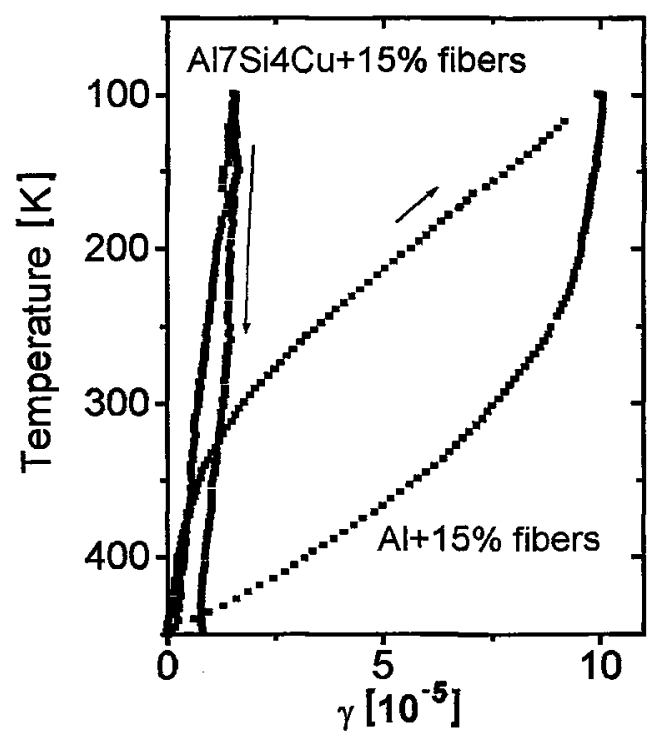

Figure 4: $\gamma$ behaviour in two composites with the same volume fraction of fibres and different matrix strength.

The overlapping temperatures given by equation (5) are included in Table I. Even when they differ from the $T_{\text {end }}$ temperatures defined in the modulus curve in about $50 \%$ in some cases, it is worth noting that no overlapping is predicted above $100 \mathrm{~K}$ for the $10 \%$ composite in coincidence with a lack of $T_{\text {end }}$ in the modulus curve. The agreement is acceptable under the present asumptions (a unique $\sigma_{y}$ is considered for all the composites and a fibre distribution without clustering). The peak temperature is about $175 \mathrm{~K}$ for all the composites so that the decrease in the internal friction at lower temperatures can not be attributed to this saturation in $f_{z p}$ but to a progressive reduction in $q_{\varphi p}$ as dislocations become less mobile.

Table I

\begin{tabular}{|c|c|c|c|c|c|c|}
\hline $\begin{array}{c}\text { Sample } \\
\% \text { vol. }\end{array}$ & $T_{0}[\mathrm{~K}]$ & $\begin{array}{c}T_{\text {start }}[\mathrm{K}] \\
\text { (from } M \text { ) }\end{array}$ & $\begin{array}{c}T_{\text {start }}[\mathrm{K}] \\
\text { (from } \gamma \text { ) }\end{array}$ & $\begin{array}{c}T_{\text {end }}[\mathrm{K}] \\
\text { (from } M)\end{array}$ & $\begin{array}{c}T_{\text {start }}[\mathrm{K}] \\
\text { (calculated) }\end{array}$ & $\begin{array}{c}T_{\text {end }}[\mathrm{K}] \\
\text { (calculated) }\end{array}$ \\
\hline $\mathrm{Al}-10 \%$ & 370 & 300 & 270 & - & 295 & - \\
\hline $\mathrm{Al}-15 \%$ & 400 & 370 & 375 & 170 & 372 & 127 \\
\hline $\mathrm{Al}-20 \%$ & 390 & 330 & 335 & 190 & 335 & 185 \\
\hline $\mathrm{Al}-30 \%$ & 395 & 350 & 350 & 180 & 351 & 258 \\
\hline
\end{tabular}

\section{Acknowledgments}

Authors gratefully acknowledge the support provided by Dr. A. Ghilarducci and Dr. A. Caro in the Internal Friction Laboratory, Metals Division, Atomic Centre of Bariloche, Argentina. E. Carreño-Morelli acknowledges the support of the Fundación Antorchas Project 13221/1-0055.

\section{References}

[1] Carreño-Morelli E., Urreta S.E., Gabella L., Schaller R., This Conference.

[2] Zhou X., Fougères R., Vincent A., J .Phys. III France, 2 (1992) 2185-2201.

[3] Girard G., Lormand G., Fougères R., Vincent A., Scripta Metall. Mater. 29, N9 (1993) 1047-1052

[4] Vincent A., Girard G., Lormand G., Fougères R., J. Alloys Comp. 211/212 ( 1994) 410-413

[5] Vogelsang M., Arsenault R., Fisher R., Met. Trans. 17A (1980) 379-384

[6] Dunand D., Mortensen A., Acta Metall. Mater., 39, N2 (1991) 127-139.

[7] Urreta S.E., Schaller R., Scripta Metall. Mater. 29 (1993) 165-170 